\title{
Um olhar da Comunicação sobre o imaginário e a pós- modernidade: entrevista com Juremir Machado
}

\author{
Lucas Santiago Arraes Rieno \\ Doutor, Universidade Federal do Maranhão, Imperatriz, MA, Brasil \\ lucas@ufma.br
}

\section{Thaísa Cristina Bueno}

Doutora, Universidade Federal do Maranhão, Imperatriz, MA, Brasil thaisabu@gmail.com

\section{Marco Antônio Gehlen}

Doutor, Universidade Federal do Maranhão, Imperatriz, MA, Brasil gehlen.m@gmail.com

\section{Ed Wilson Ferreira Araujo}

Doutor, Universidade Federal do Maranhão, São Luís, MA, Brasil edwilson_araujo@yahoo.com.br

\section{Resumo}

Entrevista com Juremir Machado a respeito da alimentação da nossa esfera simbólica promovida pela publicidade, cinema, rádio, televisão, enfim, por todas as mídias: as tecnologias do imaginário. Aborda também temas referentes à existência e construção do real; o imaginário como elemento de superfaturamento do jornalismo, que transforma ordinários em extraordinário; e as características sociais do imaginário.

\section{Palavras-chave}

Tecnologias do imaginário. Pós-modernidade. Jornalismo.

Desvendar aspectos da nossa estrutura existencial, com nossas subjetividades, ideologias, cultura e representações. Assim, Juremir Machado justifica os estudos de imaginário, que define como as narrativas produtoras de relações na sociedade da comunicação, acentuadamente, em cenário contemporâneo no qual dispomos do que o 
pesquisador chama de As Tecnologias do Imaginário, título que, também, deu nome a um de seus livros lançado em 2003 pela editora Sulina.

Doutor e mestre em Sociologia da Cultura pela Université Paris V René Descartes, graduado em história e jornalismo, Juremir Machado é professor do curso de jornalismo da Faculdade de Comunicação (Famecos) da PUC-RS e coordenador do programa de PósGraduação em Comunicação Social da mesma universidade. Nesta entrevista, o pesquisador trata da alimentação da nossa esfera simbólica promovida pela publicidade, cinema, rádio, televisão, enfim, por todas as mídias: as tecnologias do imaginário.

Abordando, ainda, temas referentes à existência e construção do real; o imaginário como elemento de superfaturamento do jornalismo, que transforma ordinários em extraordinário; e as características sociais do imaginário, Juremir Machado dá pistas, na entrevista que segue, da imersão a que se dedica a estes temas, consolidando-se como um dos mais respeitados pesquisadores da área, com valiosa contribuição para os estudos em jornalismo e em comunicação.

\section{Como podemos definir o que é o imaginário?}

Eu penso que nos últimos anos, depois de um certo desgaste de alguns conceitos, como ideologia, por exemplo, foi-se buscar um que fosse, ao mesmo tempo, mais abrangente e menos passível de certos ataques. Um conceito capaz de englobar mais elementos constitutivos das nossas atividades existenciais, não só a racionalidade, mas também não só afetividade. No imaginário tem imagens, afetos, emoções, pulsões, subjetividades, trajetos existenciais. Então, é um termo que me parece muito adequado para ser usado porque ele faz fronteira com muitos outros, se vale de muitos outros e, de alguma maneira, é mais amplo que todos esses outros. Então, eu penso que o imaginário tem relação com subjetividade, com ideologia, com cultura, com representação. Ele tem um pouco de tudo isso, mas ele é mais isso e, por ser mais do que isso, ele contempla mais aspectos da nossa, digamos assim, estrutura existencial. E, nesse sentido, é um conceito que vem se impondo, que está cada vez mais usado porque ele está em uma fronteira transdisciplinar; antropologia, sociologia, teologia, das artes, da comunicação...

Eu vejo o imaginário como uma narrativa, como uma comunicação, como algo que fica na experiência de um grupo e que conta alguma coisa sobre esse grupo. 
Por que é tão importante aprender esse conceito?

Eu acho importante entender esse conceito porque ele é útil para tentar compreender como nós vivemos e como se estrutura nossa relação com a sociedade e com uma parte essencial da sociedade que é a cultura. Muitas vezes se imagina que a cultura é simplesmente, como se dizia antigamente, o sorriso da sociedade, alguma coisa assim para o mero divertimento ou distração. Mas ela é constitutiva da nossa realidade profunda, e o imaginário é um recorte da cultura. Ele é uma maneira de apropriação da cultura.

\section{Por que trazer esse conceito para a Comunicação?}

Porque acredito que o imaginário pode ser interpretado em várias maneiras, conforme as especificidades culturais e tecnológicas de cada época. A nossa época, que é uma época profundamente midiática, midiatizada, tecnologizada, é uma época da Comunicação, por excelência. É uma época da sociedade de mídia. Acredito que esse imaginário, que antes talvez fosse muito mais espontâneo e, talvez, autoproduzido, hoje é um imaginário cada vez mais induzido pelo o que eu chamo de tecnologias do imaginário, que vai da Publicidade ao Cinema, passando pelo Rádio, pela Televisão e todas as mídias que ajudam a alimentar a nossa esfera simbólica. Então, por que trazer esse conceito para a comunicação? Porque o imaginário é uma comunicação. É produtor de relações na sociedade da comunicação.

O imaginário não seria o simbólico, o efeito de sentido da semiótica? Não seria, em tese, a mesma coisa com nome diferente?

Não! Eu não acredito que seja a mesma coisa. Como é que eu vou lhe dizer? Cada perspectiva trabalha com as palavras que acha mais adequadas. Na perspectiva de Gilbert Durand e Michel Maffesoli, simbólico e imaginário não são as mesmas coisas. Na perspectiva de Jacques Lacan, psiquianalista, também não são as mesmas coisas. Na perspectiva de Cornelius Castoriadis, não são as mesmas coisas. Então, eu diria que tem mais trabalhos na perspectiva de que não são a mesma coisa do que numa perspectiva de equivalência entre os dois. Mas isso nunca poderá eliminar que alguém diga: olha nesta perspectiva, imaginário é igual a simbólico.

Eu sempre parto de um princípio, quase assim primário: se fossem a mesma coisa não teriam nomes diferentes. Então, tem aí uma pista, por que têm nomes diferentes? 0 imaginário se alimenta de simbolismos, mas ele não esgota no símbolo. Eu diria assim, o 
símbolo seria uma emanação do imaginário, é uma pista para entrar no imaginário. 0 símbolo é como se fosse um rastro, uma luz que acende. 0 símbolo é uma revelação do imaginário. 0 imaginário também se alimenta de símbolos, agora ele não é o símbolo. Ele é mais do que o símbolo.

\section{Se o imaginário é essa construção, há espaço nessa discussão para o "real"?}

Eu não tenho dúvida de que existe o real. Eu aceito que haja uma discussão sobre o estatuto da realidade, mas assim como há quem não creia no real, e isso é lícito, eu também acredito que também é legítimo acreditar no real. Existem várias camadas de realidade. Existem camadas que eu chamaria de camadas primárias da realidade, que me parecem indiscutíveis: uma mesa é uma mesa, uma cadeira é uma cadeira, quando tem Sol, tem Sol. Essas coisas as pessoas tendem a ver, a enxergar, a aceitar, da mesma maneira. Isso para mim é o real.

É claro que existem situações na vida de todo mundo que têm um tal grau de complexidade que constituem sempre um espaço de conflito em torno do que elas são ou de como elas deveriam ser interpretadas. Então, aí, não é que não estejamos diante da possibilidade de um real, temos, na verdade, uma discussão, um litígio, para saber entre duas ou mais possibilidades, qual é a que poderia ser aceita como verdadeira. Muitas vezes não conseguimos chegar a verdade justamente porque, talvez, essa verdade não exista ou, por, nesses casos, haver um conflito de interpretações.

\section{Se há um conflito de interpretações, todo real é construído?}

Eu não diria que "todo real é construído". De uma maneira mais modesta eu diria que quase todo real é construído. Eu diria, há muito de construção na realidade. Eu diria que boa parte do tempo nós estamos nos confrontando em torno de situações para saber qual o grau de realidade nessas situações, mas não em todas. Há situações em que não há qualquer tipo de disputa porque ou essas disputas já foram resolvidas ou elas nunca existiram.

Quando a gente quer saber qual é a origem de uma doença, a ciência faz pesquisas, e durante muito tempo não consegue encontrar essa relação de causa e efeito, mas em algumas situações sim, chega lá e descobre qual é a causa que produz determinado efeito e descobre, também, o que pode evitar a produção desse efeito, anulando aquilo que a causa produziria. Então, nesse caso, nós estamos diante de algo que faz consenso. Todo mundo sabe o que provoca a dengue, há um consenso em relação a isso. Pode ser que outros fatores 
produtores venham causar a dengue um dia, se é que já não existe, eu não sou especialista no assunto, eu quero dizer que ninguém duvida que a dengue seja causada por um mosquito e não por uma formiga.

Então, há um consenso em torno disso e isso é uma realidade, hoje, indiscutível. Não quer dizer que não venha a surgir, no futuro, uma formiga causadora de dengue, tomara que não, mas hoje nós temos uma realidade constituída e isso é reproduzido. A gente pode reproduzir isso para " $\mathrm{n}$ " situações em que há um real bem constituído, perceptível e compartilhado. Todos nós que estamos aqui, por exemplo, olharíamos determinadas situações e tiraríamos as mesmas conclusões. Esse é um dos mistérios da racionalidade humana, da mente humana, da percepção humana. Somos todos diferentes e temos visões diferentes das coisas, mas sobre algumas coisas, muitas coisas, temos exatamente a mesma percepção.

Já que estamos falando de realidade, no Jornalismo existem duas correntes muito fortes que conflitam, uma que é de tradição materialista que diz que o jornalismo é uma forma de conhecimento da realidade. E outra corrente que diz que o real não existe. Focado no Jornalismo, qual dessas correntes você acha que é mais consistente ou nenhuma delas?

Não, eu não concordo com nenhuma delas. Eu não acho que o Jornalismo seja uma ciência, não acho que o Jornalismo seja uma forma específica de conhecimento da realidade. E também não acho que o real seja inacessível. Eu acho que o Jornalismo é uma forma de descrição da realidade, de descrição e opinião da realidade. 0 que faz um jornalista? Tenta descrever os acontecimentos e opinar sobre eles. Nem todo acontecimento é passível de desvendamento, muitas vezes o jornalista falha, muitas vezes ele atinge plenamente seu objetivo. Então, eu acho que é bem deliciosamente modesto, o jornalista não é um cientista e não precisa ficar aborrecido com isso, cada um na sua área.

O jornalista é um narrador, cuja a missão importantíssima é tentar contar as histórias que acontecem todos os dias, interpretar essas histórias e opinar sobre elas. Claro, a gente até faz isso. Uns descrevem, outros opinam, uns descrevem e opinam, tudo isso a gente sabe do jornalista, mas não é uma forma específica de conhecimento, é uma forma narrativa e, claro que sim, em muitos momentos a gente descreve a realidade sem dó nem piedade. Eu não tenho dúvida disso. 
Você disse que o imaginário é uma narrativa, nessa perspectiva gostaria que você falasse qual é a diferença de uma matéria jornalística comum e de outra que, digamos, teria esse adicional, essa camada extra.

Nós lidamos todos os dias com o trivial. Nós lidamos todos os dias com o imaginário. Já que estamos falando de Jornalismo, a missão do jornalista é transformar o ordinário em extraordinário. Em alguns dias, o ordinário se apresenta por si, aquilo que sabemos que é o extraordinário para os jornalistas: um acidente, uma catástrofe, uma chacina... Todas as coisas que estão lá. Há dias que não têm nada disso e quando não tem nada disso nós estamos diante do ordinário. 0 imaginário é esse extraordinário, quando algo transfigura esse ordinário.

O problema é que o papel do jornalista, todos os dias, é transformar esse ordinário em extraordinário. Isso o próprio Bourdieu diz no livro dele sobre a televisão. E como não tem extraordinário todo dia, o jornalista acaba muitas vezes forçando o traço, acaba, digamos assim, superfaturando. Muitas vezes no Jornalismo tem um superfaturamento do ordinário fazendo com que ele pareça extraordinário, tentando fazer com que aquilo se cristalize como esse excedente e, muitas vezes, não é verdadeiro, é, apenas, digamos assim, a cozinha jornalística do dia a dia. Agora, quando se está diante de alguma coisa com real poder de transfiguração, aí sim acontece outra coisa, mas não é todo dia. Na maior parte das vezes estamos lidando apenas com o ordinário.

\section{Os comentários nas notícias publicadas na internet são um plus na narrativa?}

Olha só, para mim esse é um plus, é um plus significativo, nem tudo que eu digo, que eu acrescento, é significativo, nem tudo que eu acrescento a uma situação produz aura, só é imaginário quando produz essa aura. É como se a gente tivesse o tempo inteiro tentando iluminar a cabeça de alguém, mas a maior parte do tempo não funciona, tem que produzir essa aura para ser imaginário, tem que produzir esse diferencial significativo, tem que produzir esse excedente que marca, senão não é imaginário, é simplesmente um acréscimo, um apêndice.

Mafesolli é uma referência nos estudos do Imaginário e também é o pai do conceito de sociedade tribal. Podemos dizer que o imaginário é tribal?

O Michel Maffesoli, que é um dos principais teóricos do imaginário, discípulo de Gilbert Durand, que é o grande teórico do imaginário na antropologia, entende que todo 
imaginário é social. 0 imaginário sempre expressa uma apropriação grupal em vários níveis possíveis da cultura, então, nesse sentido, o imaginário seria sempre tribal por apresentar sempre o viés, a experiência cristalizada de um determinado grupo.

Eu, particularmente, já acho que dá para pensar em um imaginário individual, o imaginário de uma pessoa. Mas eu concordo com Maffesoli que, de maneira geral, a interpretação boa é de que todo imaginário é social.

\section{Qual roteiro metodológico que poderia abarcar os estudos do imaginário?}

Bom, existem várias perspectivas. Os discípulos de Gilbert Durand, de fato, trabalham com uma perspectiva que eu diria muito assim precisa, rigorosa inclusive, com a aplicação de uma metodologia que envolve uma espécie de grade de interpretação que é um mecanismo chamado de Teste AT9. É como se fosse a aplicação de uma série de categorias dentro das quais o objeto deve se encaixar para, realmente, digamos assim, expressar um imaginário. Essa é uma possibilidade e vocês encontram isso bem descrito em um livro chamado "Sociologia do Imaginário", que a editora Sulina de Porto Alegre publicou. O texto é organizado por três professores franceses de Montpellier e que faz, em vários artigos, descrições de como trabalhar com o imaginário e apresenta metodologias para o estudo de imaginário.

$\mathrm{Eu}$, pessoalmente, não trabalho com esse tipo de perspectiva. Eu trabalho mais com a perspectiva de metodologias qualitativas que vão para a sociologia compreensiva, também usada por Maffessoli, e trabalho também com uma metodologia que eu também articulei que chamo de "narrativas do vivido" ou, então, processos do desencobrimento, que tenta contar como se vive determinada experiência e como essa vivência acaba sendo transformada em uma série de camadas em que uma camada acaba encobrindo a outra, como uma espécie de revestimento simbólico.

\section{O imaginário é pós-moderno?}

Eu acredito que todo mundo ao longo da história humana foi produtor e produzido por imaginários. 0 que eu digo é que nós estamos numa época em que isso se transformou num conceito estudado. Durante muito tempo não se existia esse conceito, portanto, não se falava nisso, mas, finalmente, isso passou a existir como uma realidade intelectual e se passou a estudar isso e, na medida em que isso passa a ser estudado, isso também tem um efeito de retroação. Na medida em que estudamos esse fenômeno, ele volta sobre nós, nós 
começamos a pensar nele e, também, a viver em torno desse conceito, que agora tem sua realidade própria.

0 que eu digo, principalmente, é que nesta nossa época altamente racionalizada, altamente tecnologizada, altamente midiatizada, o imaginário deixou de ser um conceito possível, existente na vida das pessoas, para ser algo apropriado por atores sociais com a intenção de induzir esses imaginários, de produzi-los, dominá-los, domesticá-los. Quando a gente designa um fenômeno que ninguém sabia que existia e esse fenômeno é pertinente e passa a ser visto como algo normal, passa a existir o desejo de se apropriar disso e usar isso a favor de algo.

Pierre Bourdieu quando escreveu o livro Sobre a Televisão, em que ele descreve como funcionam certas rotinas dos meios de comunicação, os críticos dos meios de comunicação se entusiasmaram e passaram a usar aquele livrinho. Mas na França, a TF1, principal rede de televisão francesa, a Globo francesa, também pegou o livrinho, adotou e fez seminários com seus funcionários para tentar corrigir o que fosse passível de correção, para se defender de determinadas acusações.

Jean Baudrillard, que era um sujeito muito irônico e cáustico, toda vez que fazia a descrição sobre as coisas e cobravam dele soluções dizia: eu não faço manual de utilização. Quer resolver um problema? Procura um manual de utilização, eu me contento em dizer como as coisas são. Mas a verdade é que, quando as pessoas dizem como as coisas são, se esse dizer é bem feito, mesmo aqueles que estão sendo implicados nisso ou estão sendo acusados de algo, vão tentar fazer uso.

Então, o imaginário não é só mais uma descrição, não é só mais uma identificação, é algo que se quer produzir e atingir. Se as pessoas têm imaginários, por que não os produzir?

O pensamento pós-moderno se organiza com base na negação das metanarrativas, a exclusão do sujeito, da racionalidade. 0 que sobra de substancioso se a gente exclui o sujeito, a razão, exclui as metas narrativas?

Eu acho que sobra muita coisa. 0 que a gente perde? A gente perde uma certa arrogância, uma arrogância na razão, a gente não perde a razão, os pós-modernos não dizem que não há razão, eles dizem que não há só a razão e que nós, seres humanos, não somos movidos só pela razão, ou fundamentalmente pela razão. Nós somos um misto de razão, emoção, pulsões, objetividades, subjetividades e que a modernidade foi a crença de que nós éramos fundamentalmente a razão. 
A pós-modernidade não é uma narrativa de desencantamento, ao contrário, ela está só dizendo que, a narrativa moderna foi uma narrativa enganosa, uma narrativa que tentou fazer crer que havia um homem profundamente racional, que pela sua racionalidade como sujeito chegaria a uma situação plena de emancipação. A pós-modernidade diz não, nós vamos passar a história da modernidade negociando, maiores ou menores graus de emancipação, vamos usar sempre a razão, mas não seremos nunca só racionais, em alguns momentos vai aflorar a irracionalidade, a não racionalidade sobre a razão, e todos nós somos assim.

Um cardiologista extremamente competente que faz as operações mais perigosas, delicadas, tudo isso é razão, depois o sujeito vai à missa, ao Candomblé, vai aqui, ali. Esse homem da razão é também o homem da "desrazão". É o homem da não-razão. É o homem da crença, da fé. Todos nós somos assim. A pós-modernidade só acentuou essa ideia de que somos assim e seremos assim, e que há riqueza nisso.

Uma perspectiva moderna acentuava que a religiosidade era superstição, era ignorância, era pobreza simbólica na qual nós deveríamos nos livrar. Morin vai dizer: não! Há muita riqueza nessa suposta ignorância, um mundo sem religião seria um mundo muito mais pobre. Então, pós-modernidade é uma apropriação do ecletismo do mundo, ela nos diz assim: não dá para definir em termos de isto ou aquilo, mas só em termos de isto e aquilo. Somos racionais, claro, e somos irracionais também. Somos racionais, irracionais, não racionais e, em determinados momentos, absolutamente animais e selvagens.

\section{Você se considera um pós-moderno?}

Olha, eu tenho muita simpatia pelo discurso pós-moderno. Eu acho que é uma narrativa extremamente interessante, modesta, extremamente modesta. Os pós-modernos são muitos, e alguns nunca se viram como tal. 0 moderno que eu admiro muito, sempre foi descrito como pós-moderno, nunca se viu como tal. 0 Morin é descrito como pós-moderno e nunca se viu como tal. O Debord nem passou pela cabeça dele considerar essa possibilidade. O Maffesoli sim, se diz um pós-moderno. O Lyotard escreveu um livro sobre a pósmodernidade, mas ele nunca disse que era pós-moderno. 0 que eu quero dizer com isto? Bom, aqueles que escrevem sobre a pós-modernidade são contra, como o Frederic Jamerson. Tudo é possível, por exemplo, Boaventura de Sousa Santos é um marxista pós-moderno. Então, são muitos cruzamentos possíveis. 
Eu gosto da pós-modernidade, principalmente naquilo que ela tem de crítica a determinadas ilusões da modernidade, por exemplo, a ilusão do progresso contínuo, libertador e emancipador. A ideia de que as sociedades caminhariam de uma etapa para outras sucessivas, emancipadoras, que finalmente nós chegaríamos a essa estação final de emancipação. Eu acho que a pós-modernidade tem razão em dizer isso, isso não vai acontecer.

\title{
Referências
}

BOURDIEU, Pierre. Sobre a televisão. Rio de Janeiro: Zahar, 1997.

LEGROS, Patrick et al. Sociologia do imaginário. 2. ed. Porto Alegre: Sulina, 2014.

SILVA, Juremir Machado da. As tecnologias do imaginário. Porto Alegre: Sulina, 2003.

\section{A look from the Communication about imaginary and postmodernity: interview with Juremir Machado}

\begin{abstract}
Interview with Juremir Machado about the feeding of our symbolic sphere promoted by advertising, cinema, radio, television, and in all media: the technologies of the imaginary. It also covers themes related to the existence and construction of the real; the imaginary as an element of super-billing of journalism, which turns ordinary into extraordinary; and the social characteristics of the imaginary.
\end{abstract}

\section{Keywords}

Technologies of the imaginary. Postmodernity. Journalism.

Recebido em 22/03/2017

Aceito em 08/10/2017 